\title{
Covid-19 y migración en la frontera noreste de México: los casos de las casas de asistencia para migrantes
}

\section{The Covid-19 pandemic in the assistance houses for migrants on the northeast border of Mexico}

Cynthia Marisol Vargas Orozco*

Karla Villarreal Sotelo*
Recibido: 10-12-2021

Aceptado: 10-01-2022

\section{Resumen}

La migración es un fenómeno social de gran relevancia en la comprensión de las condiciones sociales, políticas, económicas y ambientales de los países, sin embargo, el surgimiento de la pandemia del Covid-19 ha puesto en escenario nuevos desafíos a este fenómeno con profundos impactos en la migración. El presente estudio tiene como objetivo documentar el contexto migratorio durante la pandemia del Covid-19 en la frontera noreste de México a través de las Casas de Asistencia para Migrantes (CAM)

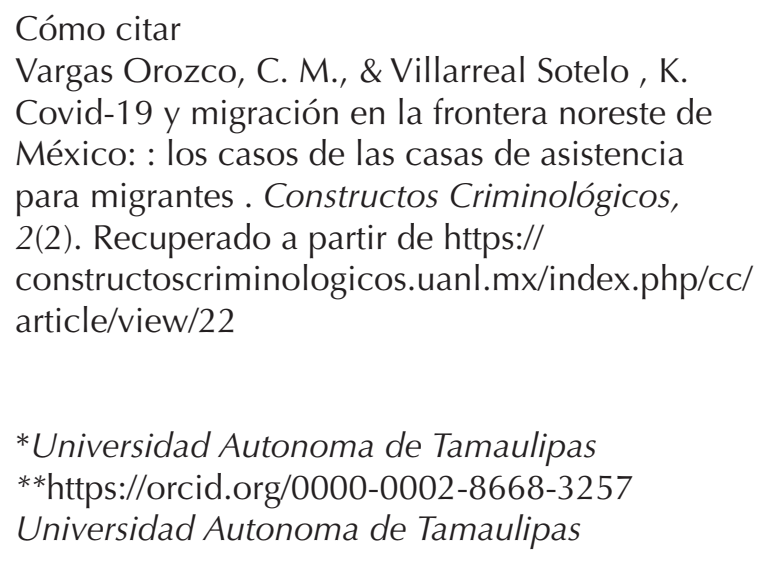

de la ciudad de Reynosa Tamaulipas desde una perspectiva criminológica, para cumplir con este objetivo se analizan las frecuencias y datos demográficos de personas migrantes atendidas en las CAM durante el año 2020, y se describen las estrategias de protección de la salud para atender y prevenir los contagios de Covid-19 en estos lugares. Encontrando que las CAM han desarrollado estrategias de acuerdo a sus capacidades para hacer frente a los retos y desafíos de la migración en un contexto de vulnerabilidad no sólo social, sino sanitaria.

Palabras clave: Covid-19, Migración, Salud Pública, Grupos Vulnerables, Fronteras

\section{Abstract}

Migration is an important social phenomenon to understand the social, political, economic and environmental conditions of the countries, however, the emergence of the Covid-19 pandemic has brought new challenges with profound impacts on the migration processes. 
The present study aims to document the migratory context during the Covid-19 pandemic on the northeast border of Mexico through the Assistance Houses for Migrants (AHM) in the city of Reynosa Tamaulipas from a criminological perspective, to meet this objective we analyzed the frequencies and demographic data of migrants treated in AHM during 2020, and health protection strategies are described to attend and prevent Covid-19 contagions in these places. Finding that the AHM have developed strategies according to their capacities to face the challenges of migration in a context of vulnerability not only social, but also health.

Keywords: Covid-19, Migration, Public Health, Vulnerable Groups, Borders

\section{INTRODUCCIÓN}

El La migración es un fenómeno social en incremento en las últimas décadas, en el cual, se encuentran inmersos factores sociales, políticos, económicos, culturales, naturales educativos, religiosos, entre otros (Gómez-Walteros, 2010:84). La migración ha estado relacionada a entornos de inseguridad y vulnerabilidad debido las condiciones bajo las que se realiza y a su vez por el endurecimiento de las políticas migratorias actuales (Izacara-Palacios, 2012; Carpio et al., 2017) y recientemente agravada por las condiciones sanitarias derivadas de la pandemia del SARS-CoV-2 (Covid-19).

La frontera norte de México, en el principal corredor migratorio del planeta (Organización Internacional para las Migraciones, 2020), el estado de Tamaulipas es geográficamente la ruta de acceso más corta a los Estados Unidos (Barrón, 2013; Carpio-Domínguez et al, 2017) caracterizándose por la presencia de importantes flujos migratorios (Izcara-Palacios, 2012). Este estado mexicano constituye un centro receptor y expulsor de jornaleros migratorios tanto nacionales como internacionales (IzcaraPalacios, 2012; Izcara-Palacios y Andrade-Rubio, 2015), los cuales, tienen como objetivo llegar a Estados Unidos en busca de trabajos temporales, o bien, migran definitivamente buscando mejores oportunidades de desarrollo (Alba, 1979).

La principal respuesta ante la pandemia del Covid-19, fue el aislamiento social y el aumento de la vigilancia sanitaria en las principales entradas a los países, por lo que estas medidas de seguridad tuvieron profundos impactos en el proceso migratorio. Al respecto, ante la emergencia de la pandemia, el gobierno de Estados Unidos en el discurso de que la migración atenta contra la seguridad nacional en la propagación del coronavirus (Sedas et al, 2020) derivó en el aumentó las patrullas fronterizas, estableciendo requisitos más estrictos para obtener asilo o visas y presionó a México y a los países centroamericanos para que procesen las solicitudes de asilo presentadas en los EE. UU. (a través de los Ilamados Protocolos de Protección al Migrante y los Acuerdos de Cooperación de Asilo). Estas medidas ayudaron a reducir en un $70 \%$ el número de centroamericanos en la frontera sur de Estados Unidos y norte de México (International Crisis Group, 2020).

Fue evidente que debido a la pandemia por el Covid-19 las personas migrantes 
fueron concebidas como un grupo aún más vulnerable, por lo que tanto instituciones del Estado mexicano como organizaciones no gubernamentales, desplegaron un abanico de políticas y acciones públicas enfocadas en dicha población para prevenir contagios, o bien, para atender brotes. Ante este panorama, el reto concep- tual que planteó este artículo fue cómo concebir las políticas públicas y acciones públicas, por un lado, y cómo captar sus matices para un caso particular del norte de México (HernándezHernández, 2021: 67).

Sin embargo, la migración no se detuvo con la implementación de estas medidas sanitarias, las personas migrantes tanto nacionales como extranjeras continuaron Ilegando a la frontera norte de México, mientras que las políticas implementadas por el gobierno de México para incluir a la población migrante en la respuesta nacional contra el Covid-19, no ha sido efectiva en permear el impacto de la pandemia en la este grupo social, derivando en el contagio también de personas migrantes mientras residen en la frontera norte del país (Gobierno del Estado de Tamaulipas, 2020; Sedas et al, 2020)

La importancia de este estudio radica en que se profundiza en el contexto migratorio de la pandemia del Covid-19 en el estado de Tamaulipas por lo que es fundamental comprender cómo diversos actores sociales y organizaciones no gubernamentales contribuyen en la gobernanza sanitaria y en la protección de los derechos humanos también en materia de salud de las personas migrantes en el estado.

\subsection{La pandemia en la migración}

A finales del año 2019 se dio a conocer a nivel mundial el surgimiento de un nuevo coronavirus denominado SARS-CoV-2 (Covid-19) (Zhou et al., 2020) el cual, se distribuyó a nivel mundial favorecido por la globalización y las comunicaciones aéreas entre los países y las regiones, ocasionando una pandemia que ha tenido profundos impactos económicos, ambientales, sociales y en la salud humana sin diferenciar clases y estratos sociales, ni países desarrollados o en desarrollo (Aja, 2020).

Para el 11 de marzo de 2020, la Organización Mundial de la Salud (OMS) en comunicación oficial, declaró el brote del coronavirus SARSCoV-2 como una pandemia global, indicando que cada país debía reforzar sus estrategias para atender esa emergencia sanitaria (OMS, 2020). Teniendo como consecuencia 1) los contagios, los cuales suman alrededor de 50 millones de personas y más de un millón de muertes por Covid-19 a nivel global, y la exclusión social de personas por miedo al contagio, 2) las medidas de prevención de contagio del Covid-19 como el aislamiento, la cuarentena y el toque de queda, 3) las pérdidas económicas y el desempleo, y 4) las muertes de familiares, amigos y personas conocidas (Griffiths y Mamun, 2020; Sher, 2020; D’Souza et al. 2020). Las principales estrategias tomadas por los gobiernos de la mayoría de los países del mundo han sido el aislamiento, la protección personal (bioseguridad), diagnóstico temprano y tratamiento (para síntomas) en pacientes infectados (Macintosh, 2020).

Esta situación, puso a prueba a los diferentes gobiernos, sociedades y particulares, ya que 
implicó la protección de todos los derechos humanos, económicos, sociales y culturales, teniendo que asumir la implementación y cumplimiento de diferentes acciones que resguardaran a la población, el acceso a la atención médica, las medidas de emergencia, la vivienda, alimentación, saneamiento e higiene a todas las personas, incluyendo a las personas en condición de vulnerabilidad, minorías, migrantes, pueblos indígenas, desplazados, personas recluidas y detenidas (Oficina de Alto Comisionado de las Naciones Unidas para los Derechos Humanos, OACNUDH, 2020a). Las personas más vulnerables a esta crisis son las que ya están riesgo, aquellas que no tienen acceso adecuado a la vivienda, al agua potable, así como aquellos que sufren de discriminación y los que por su condición social se encuentran en desventaja.

En este sentido, uno de los grupos sociales con mayor vulnerabilidad es la población migrante (OACNUDH, 2020b). La mayoría de los migrantes, viven en asentamientos, campos con sobrepoblación, centros de recepción, refugios que son improvisados y por sus situaciones precarias, estos lugares no ofrecen un adecuado sistema de salud, por lo que se encuentran en condiciones de insalubridad, de hacinamiento, lo que hace que las consecuencias de un brote de Covid-19 sea letal (OACNUDH América Central, Oficina Regional, 2020c).

Para atender la situación de los migrantes frente a la emergencia sanitaria que se enfrenta globalmente por la Covid-19, la Oficina de Alto Comisionado de las Naciones Unidas para los Derechos Humanos, el 7 de abril de 2020, puso en circulación "Covid-19 y los Derechos
Humanos de los migrantes: Guía" en la cual, se especifican las diferentes acciones que deben tomarse para proteger la salud de aquellos que viven en albergues, estas acciones comprenden: provisiones de agua, saneamiento e higiene, la provisión de todos los servicios esenciales, incluida la alimentación, prevención, pruebas y tratamientos (OACNUDH, 2020d).

Ante esta apreciación, el 30 de marzo de 2020 el Consejo de Salubridad de México declaró a la epidemia generada por el virus SARS-CoV-2 como emergencia sanitaria de fuerza mayor, llevando al Estado Mexicano a determinar las acciones necesarias para atender las diferentes problemáticas que traería esta declaración (Gobierno de México, 2020a). Esto derivó en la publicación de las guías de salud pública para la prevención de la transmisión de Covid-19, exhortando inmediatamente la suspensión de toda actividad no-esencial a través del sector público, privado y social además de las recomendaciones de "distanciamiento social" (Secretaría de Salud, 2020).

\subsection{Contagios de Covid-19 en Tamaulipas, México}

La contingencia sanitaria originada el Covid-19 en el estado de Tamaulipas, inició seis días después (17 de marzo) de la declaración como pandemia por parte de la Organización Mundial de la Salud (11 de marzo). El Comité Estatal para la Seguridad Publica en Salud implementó acciones de coordinación para la suspensión de actividades escolares, limitar el acceso a las playas y la reducción de la asistencia del personal a los centros de trabajo, así como la suspensión de manera inmediata de 
Figura 1. Comportamiento de casos de contagios de Covid-19 en el estado de Tamaulipas durante 2020

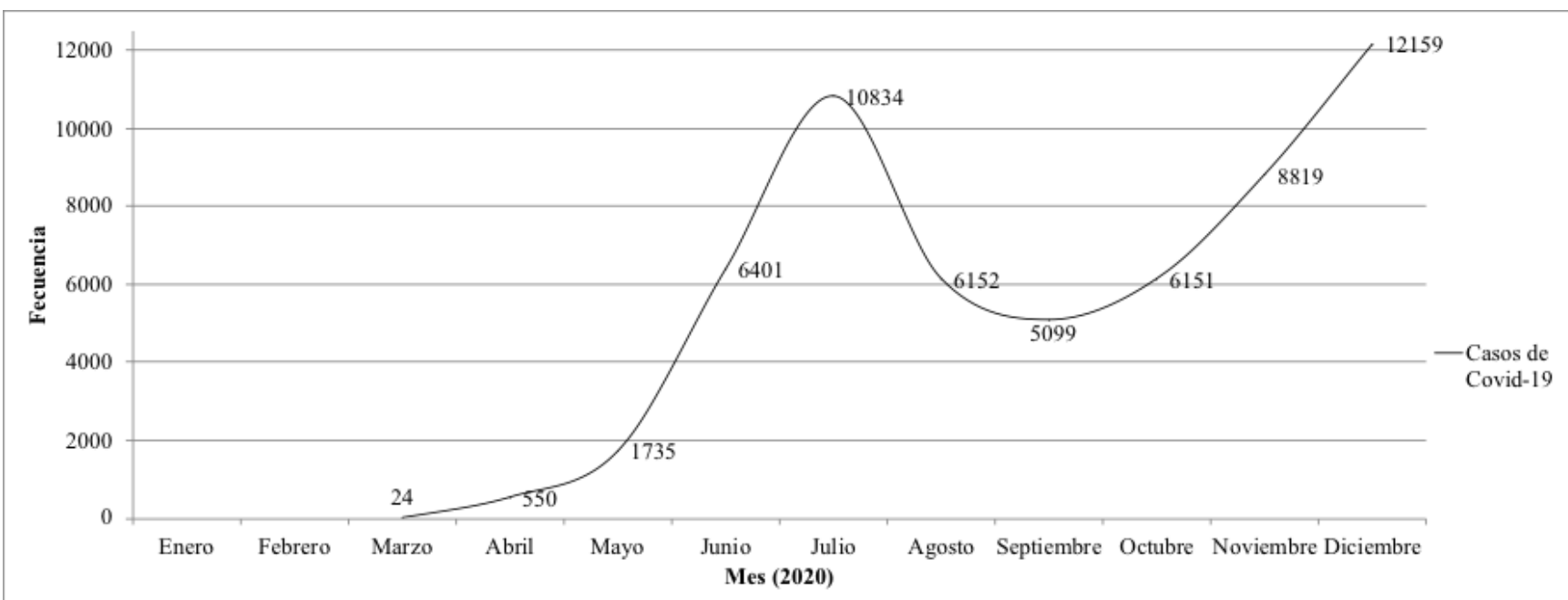

Fuente: elaboración propia con datos de los datos epidemiológicos oficiales de la página de Gobierno de México

eventos sociales, centros recreativos y cualquier actividad que implique aglomeraciones sociales (Gobierno del Estado de Tamaulipas, 2020).

La frecuencia de casos de contagios de Covid-19 en el estado ha presentado dos grandes incrementos, la primera curva de contagio o curva epidemiológica ${ }^{1}$ tuvo la frecuencia más alta en el mes de julio con 10,834 casos de contagios con un descenso de casos de Covid-19 en el estado durante los meses de agosto ( $n=6152)$ y septiembre ( $n=5$ 099), siendo los registros más bajos de contagios desde el inicio

\footnotetext{
$1 \quad$ La curva epidemiológica es un gráfico estadístico utilizado en epidemiología para visualizar el inicio de un brote epidémico, la cual, permite identificar la magnitud de la enfermedad, valores atípicos, tendencia en el tiempo, periodo de incubación, etc. (Torok, 2002)
}

de la pandemia en el estado. Sin embargo, en el último trimestre el incremento en el número de casos de contagio se ha sostenido, alcanzando en diciembre un total de 12,159 casos de contagios extendiendo la segunda curva de contagios hasta $2021^{2}$ (Figura 1).

Sin embargo, en este escenario de contagios, también figuraron las personas migrantes que residen en el estado, ya que el 20 de abril de 2020 el Gobierno del Estado de Tamaulipas confirmó el contagio de 198 personas por el coronavirus SARS-CoV-2, de los cuales el $10 \%$ de este grupo correspondía a población migrante nacionales y extranjeros deportados, establecidos en albergues de la frontera. Este

\footnotetext{
2 Hasta la elaboración del presente estudio (enero, 2021), la segunda curva epidemiológica no se ha definido.
} 
10\% correspondía a 16 migrantes, contagiados en un albergue de los cuales, 6 eran originarios de Honduras, 4 de México, 3 de Cuba, uno de Guatemala, uno de Camerún y por último uno sin determinar su lugar de origen (Gobierno del Estado de Tamaulipas, 2020; Sedas et al, 2020). Esto anterior derivó en que el Gobierno de Tamaulipas presentara ante la Suprema Corte de Justicia de la Nación una Controversia Constitucional, de carácter urgente, en la que solicitó se dictaran medidas sanitarias para la protección de la salud también de los migrantes que se encuentran en el estado. Esta situación permite entrever, que la población vulnerable como los migrantes en el contexto de la pandemia del coronavirus se ha convertido en un desafío para la gobernanza en salud inclusiva, la capacidad del Estado para enfrentarla y prevenirla y en la reducción de las desigualdades (Riggirozzi, Grugel y Cintra, 2020).

\section{METODOLOGÍA}

\subsection{Tipo de estudio}

El presente estudio descriptivo se realizó a través un enfoque mixto, que de acuerdo a Creswell (2008), este enfoque mixto permite integrar en un mismo estudio, metodologías cualitativas y cuantitativas, orientado a ampliar la comprensión del fenómeno que se estudia. Este tipo de estudio permite comprender las interrelaciones entre las variables de análisis ofreciendo una síntesis interpretativa (complementación) de los resultados de cada método (Bericat, 1998).

\subsection{Población de estudio}

Se analizan los datos cualitativos y cuantitativos de las dos Casas de Asistencia para Migrantes (CAM) en la ciudad de Reynosa Tamaulipas: Albergue Nuestra Señora de Guadalupe y el Albergue Senda de Vida; con el objetivo de conocer las cifras de personas migrantes atendidas en las casas de asistencia para migrantes, así como describir las estrategias de protección de la salud y los principales desafíos para atender y prevenir los contagios de coronavirus durante la pandemia del SARS-CoV-2 (Covid-19) en el periodo enerodiciembre del 2020.

\subsection{Recolección y análisis de datos}

Para cumplir con los objetivos planteados 1) se analizaron por estadística descriptiva las frecuencias y datos socio-demográficos de personas migrantes atendidas en las CAM, y 2) a través de entrevistas semiestructuradas con los directores de las CAM se analizan las principales estrategias de prevención de contagios de coronavirus (SARS-CoV-2 ) y los desafíos para el funcionamiento de estos albergues durante la pandemia en el periodo enero-diciembre 2020. En cuanto a la combinación de los métodos, se utiliza la complementariedad de la información que de acuerdo a Greene et al. (1989) y Bryman (2006) la complementariedad en los método mixtos busca la elaboración, mejora, ilustración y aclaración de los resultados de un método con los resultados del otro (Greene et al., 1989: 259; Bryman, 2006: 105).

Esta metodología es aplicada para analizar, en un primer momento, los datos cuantitativos 
de ambas casas de asistencia, de los cuales, se analizan primero los datos de manera conjunta y posteriormente por cada una de las CAM, debido a que los procedimientos, características, capacidades y criterios para la atención de personas migrantes son distintos en cada una. En cuanto a las variables cuantitativas se analizan datos como: número de personas recibidas/atendidas, género, número de menores de edad, lugares de procedencia (nacionales y extranjeros) y padecimientos médicos identificados (diagnosticados).

Respecto a los datos cualitativos, se analizan desde dos categorías previas: 1 ) retos y desafíos para la prevención de contagios de Covid-19 en migrantes, y 2) estrategias de prevención de contagios durante la emergencia sanitaria. La primera categoría tiene como objetivo comprender las afectaciones (económicas y administrativas) al funcionamiento de las CAM derivadas de la contingencia sanitaria, mientras que la segunda categoría comprende las estrategias implementadas por las CAM para hacer frente a la contingencia para salvaguardar la salud y atención a las personas migrantes durante el periodo de estudio.

\section{RESULTADOS Y DISCUSIÓN}

Para comprender la importancia de las Casas de Asistencia para Migrantes (CAM) en la frontera noreste de México, es necesario mencionar que esta región fronteriza es uno de los principales puntos de recepción de personas migrantes, durante 2020 de los 87 260 migrantes extranjeros presentados ante la autoridad migratoria mexicana 16392 (19.79\%) fueron en Tamaulipas (ocupando el segundo lugar nacional después del estado de Chiapas), siendo además, el principal estado fronterizo por el que se realizó el mayor numero de eventos de repatriación de migrantes por parte de Estados Unidos con un total de 58814 (31.8\%) (Gobierno de México, 2020b).

La ciudad de Reynosa, recibe una gran cantidad de personas migrantes tanto nacionales como extranjeros que buscan cruzar hacia Estados Unidos y que son atendidos por las CAM, por lo cual, tienen un rol fundamental en el proceso migratorio en la frontera norte de Tamaulipas ya que reciben a hombres, mujeres y menores migrantes que van de paso hacia Estados Unidos o de retorno a México a lo largo de toda la región fronteriza (Varela-Huerta, 2016; Carrasco-González, 2017; Castillo-Ramírez, 2020). Las CAM de Reynosa reciben a personas migrantes deportadas por otros puentes fronterizos generalmente provenientes de la ciudad de Matamoros (al este) o bien desde Nuevo Laredo (al noroeste), de igual manera reciben aquellas personas que van de paso con destino a Estados Unidos o bien van de regreso a sus lugares de origen en México. En estas casas se ofrece comida, hospedaje, atención médica, acceso a comunicación con los familiares de las personas alojadas, asistencia legal y vinculación con el Instituto Tamaulipeco para los Migrantes para facilitarles un retorno seguro a sus lugares de origen.

\subsection{La migración, casas de asistencia y la pandemia del Covid-19}

Durante el año 2020 las casas de asistencia de la ciudad de Reynosa recibieron 3538 personas migrantes, de las cuales, el Albergue Nuestra 
Señora de Guadalupe (ANSG) atendió a 3 108 personas migrantes $(87.8 \%)$ y el Albergue Senda de Vida (ASDV) recibió 430 personas migrantes $(12.1 \%)$. Estas cifras responden a los distintos procedimientos, capacidades y criterios de cada albergue, ya que el ANSG recibe personas migrantes durante tres días, en los cuales se les ofrecen los servicios mencionados y posteriormente dejan la casa para permitir a otras personas ingresar, por lo que la población atendida en esta casa es mayor, en tanto que el tiempo de permanencia por persona está restringido a los tres días, mientras que el ASDV ofrece los servicios a las personas hasta que tienen algún tipo de seguridad como trabajo, casa, etc.
Previo al inicio de la medida de seguridad de contingencia sanitaria (aislamiento) en el estado de Tamaulipas (en marzo 2020), ambas casas de asistencia recibieron 1082 personas durante el primer bimestre (enero-febrero), lo que representa el $50.9 \%$ del total anual, mientras que el resto del periodo (marzo-diciembre) recibieron una población de 1736 personas migrantes, es decir el $49 \%$ del total anual. Al inicio de la contingencia sanitaria en el estado, hubo un descenso del $34.3 \%$ en la frecuencia de atención de personas migrantes durante el mes de marzo ( $n=837,18.1 \%$ ) respecto a febrero $(n=1275,27.6 \%)$, este descenso se mantuvo en los próximos meses en función a la primera curva de aumento de contagios durante el mes de julio (ver Figura 1) con un aumento en el último trimestre del año (Figura 2).

Figura 2. Frecuencias de personas migrantes atendidas por las casas de asistencia en la ciudad de Reynosa, Tamaulipas durante el año 2020

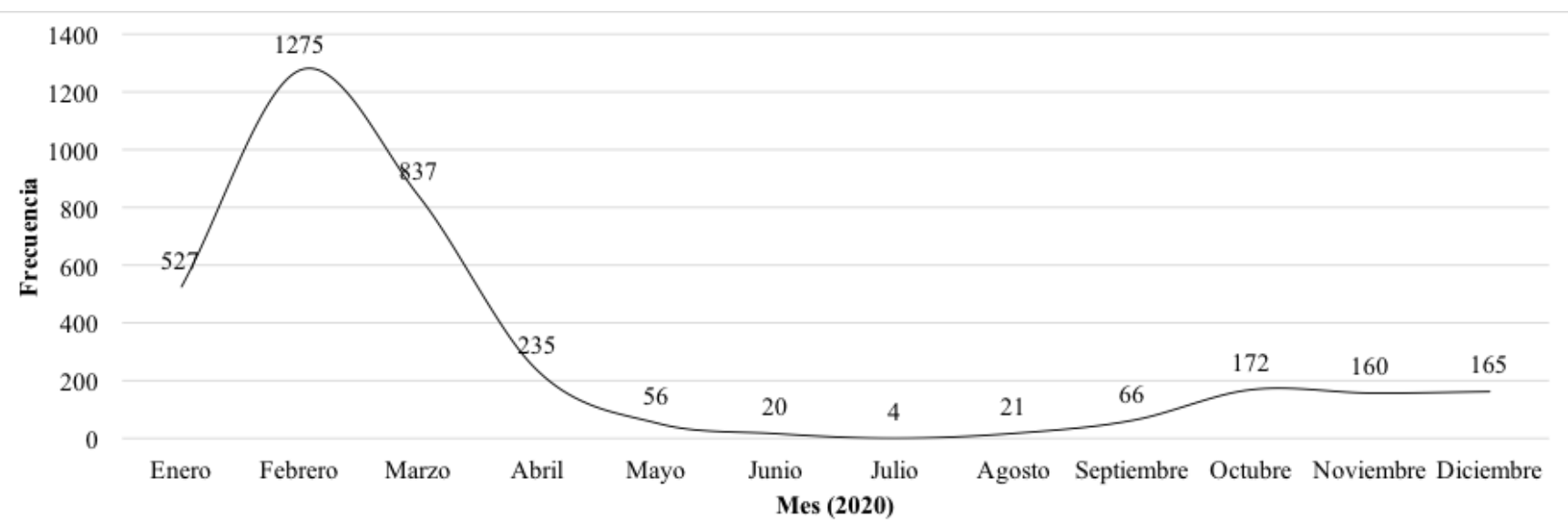

Fuente: elaboración propia con datos de las Casas de Asistencia para Migrantes (2020)

Se identificó que previo al inicio de la $48 \%$ del total de personas recibidas durante contingencia sanitaria (marzo, 2020) el ASNG 2020, mientras que durante la contingencia recibió 1492 personas, lo que representó el sanitaria (marzo-diciembre) este albergue 
atendió al 52\% ( $\mathrm{n}=1616)$ sumando un total anual de 3108 personas migrantes, así como a 217 personas menores de 18 años. Una vez iniciada la contingencia, se registró un descenso del $67.1 \%$ de personas atendidas en el mes de abril $(n=235,7.6 \%)$ respecto al mes de marzo ( $n=717,23.1 \%$ ) (Figura 3), situación que continuó en descenso coincidiendo con la primera curva de contagios del SARS-CoV-2
(Covid-19) en el estado (Ver Figura 1) ya que durante el periodo junio-agosto la curva de contagios visibilizó la gravedad de la pandemia en el estado y en consecuencia la frecuencia de atención a personas migrantes fue menor, ya que la principal estrategia para prevenir y contener los contagios fue el aislamiento, y que las casas de asistencia también tuvieron que implementar durante la pandemia.

Figura 3. Frecuencias de personas migrantes atendidas por las casas de asistencia en la ciudad de Reynosa, Tamaulipas durante el año 2020

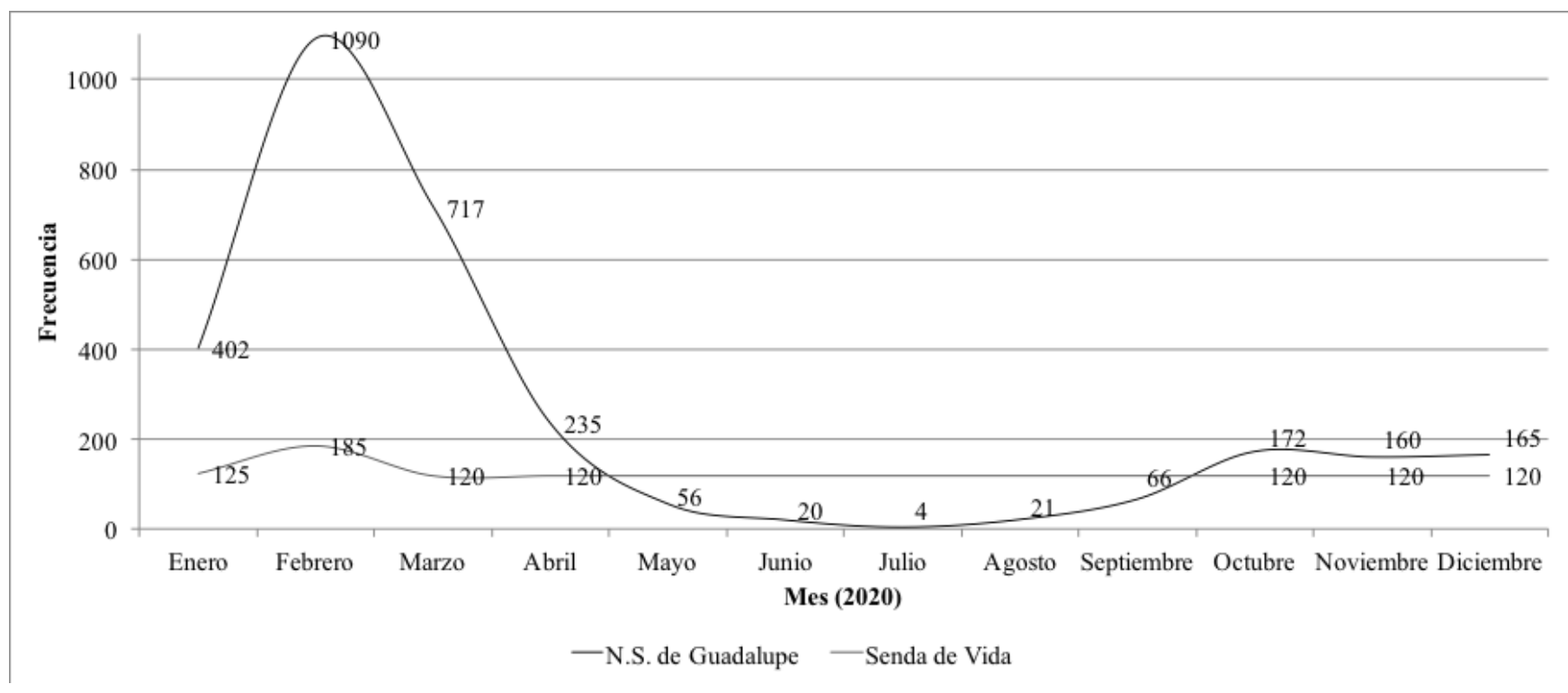

Fuente: elaboración propia con datos de las Casas de Asistencia para Migrantes (2020)

A partir del mes de septiembre se evidenció un aumento en la frecuencia de personas migrantes recibidas en el ANSG $(n=66,2.1 \%)$ situación que continuó en aumento hasta el mes de octubre $(n=172,5.5 \%)$, esto anterior responde al descenso de la curva de contagios durante septiembre $(n=5099)$ y octubre $(n=6151)$; sin embargo, con el incremento sostenido de contagios en el último trimestre de
2020, la atención de personas migrantes en el ANSG tuvo que descender, cerrando el mes de diciembre con 165 personas (5.3\%) recibidas.

Por otra parte, el Albergue Senda De Vida (ASDV) recibió 430 personas migrantes durante 2020 , de las cuales el $72.1 \%(n=310)$ fueron recibidas en el primer bimestre previo a la contingencia sanitaria, mientras que el $27.9 \%$ 
fue recibido en los meses restantes del año. Es necesario establecer que a diferencia del ANSG, este albergue mantuvo durante la contingencia (marzo-diciembre) a 120 personas durante todo el periodo. Esta dinámica corresponde a las medidas de seguridad implementadas por el ASDV para prevenir los contagios dentro de sus instalaciones. En el mes de enero atendieron a $125(29 \%)$ personas con un aumento del $48 \%$ respecto al mes de febrero $(n=185,43 \%)$, siendo el mes con el mayor número de personas atendidas.

En cuanto al periodo de contingencia de 2020 correspondiente a marzo-diciembre, el ASDV mantuvo la población que ingresó en el mes de marzo $(n=120,27.9 \%)$ hasta diciembre (Figura 3). Durante este periodo, el ASDV les proporcionó hospedaje, alimentación, y asistencia médica y legal a las 120 personas las cuales eran originarias de Latinoamérica y África, así como a 110 menores de 18 años. Con relación a la distribución por género de las personas migrantes atendidas por las CAM, se identificó que la frecuencia de hombres es mayor ( $n=2639,82.2 \%$ ) respecto a las mujeres ( $n=572,17.8 \%$ ), se evidencia que la frecuencia de personas atendidas por las CAM durante la contingencia del Covid-19 corresponde porcentualmente a hombres. Se observó un descenso en las frecuencias entre hombres $(66.6 \%)$ y mujeres $(84.6 \%)$ durante el mes de marzo respecto a febrero, ya que en el caso de los hombres la frecuencia de hombres durante febrero fue de 1045 (39.6\%) frente a 601 $(22.8 \%)$ en marzo, mientras que las mujeres descendieron de $176(30.8 \%)$ en febrero a 27 $(4.7 \%)$ en marzo (Figura 4$)$.

Figura 4. Distribución por género de personas migrantes recibidas en las casas de asistencia de la ciudad de Reynosa, Tamaulipas durante el año 2020

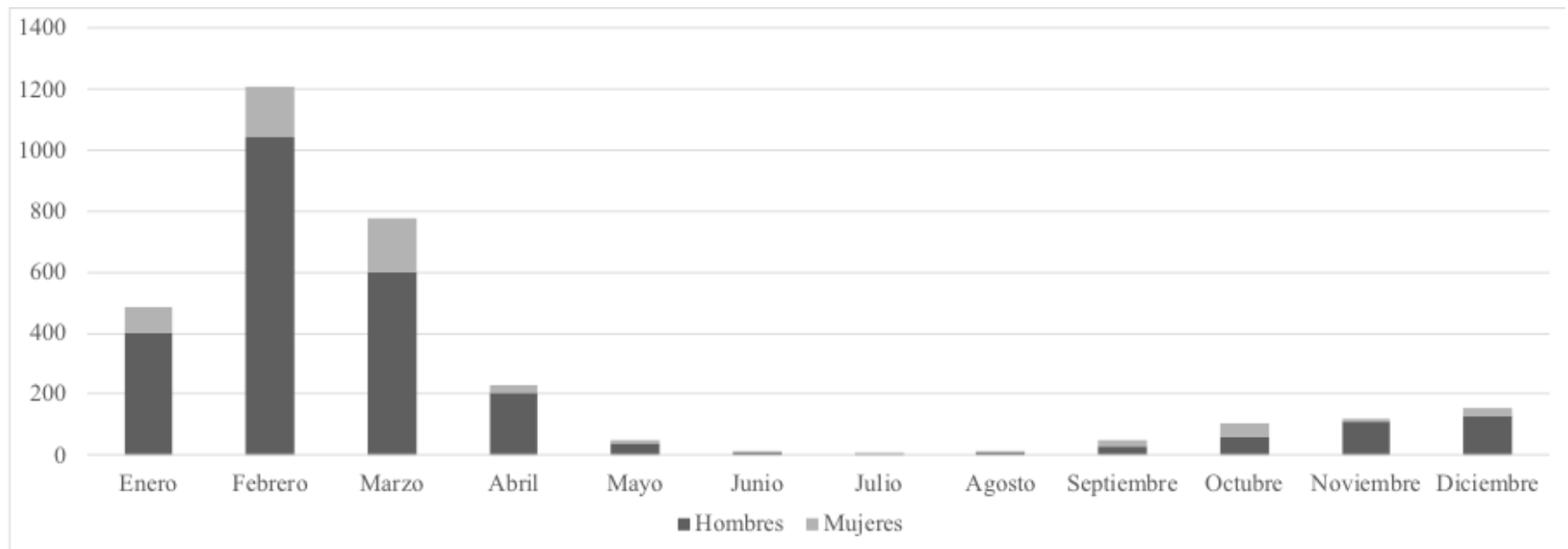

Fuente: elaboración propia con datos de las Casas de Asistencia para Migrantes (2020)

Durante la primera curva de contagios de Covid-19 en el estado de Tamaulipas en los meses de junio y julio (ver Figura 1), las

frecuencias por género fueron de $0.4 \%(n=13)$ en junio y de $0.1 \%(n=3)$ en julio, siendo las 
menores del periodo de estudio. La distribución por género durante este bimestre estuvo representada en el mes de junio por $10(0.4 \%)$ hombres y $3(0.5 \%)$ mujeres; mientras que durante julio se recibieron 2 hombres $(0.1 \%)$ y una mujer $(0.2 \%)$.

Las CAM recibieron durante este periodo a 327 personas menores de 18 años representando el $9.2 \%$ del total de población migrante durante 2020 atendida en las CAM (ANSG=217, $A S V D=110$ ). Este fenómeno de menores de edad en el proceso de migración, ha sido documentado en la última década como un fenómeno en aumento (Hernández-Hernández, Vargas-Orozco y Villarreal-Sotelo, 2015), evidenciando un cambio en los procesos migratorios tradicionales, en donde ya no únicamente migran las personas adultas.
En los datos proporcionados por las casas de asistencia los menores de edad son contabilizados aparte del resto de la población, no especificando cuántos de ellos son hombres y mujeres; sin embargo, los datos permiten evidenciar que este grupo social muestra un comportamiento de frecuencias similar al de los adultos, con la excepción de que durante el mes de octubre tuvo un aumento considerable en la frecuencia de casos de menores atendidos por las casas de asistencia, este aumento representó el $21.4 \%(n=70)$ del total de menores durante el periodo, incluso sobre el total por mes durante el primer bimestre del año previo al inicio de la contingencia sanitaria en el estado (Figura 5).

Figura 5. Menores migrantes atendidos en las casas de asistencia para migrantes de la ciudad de Reynosa, Tamaulipas durante el año 2020

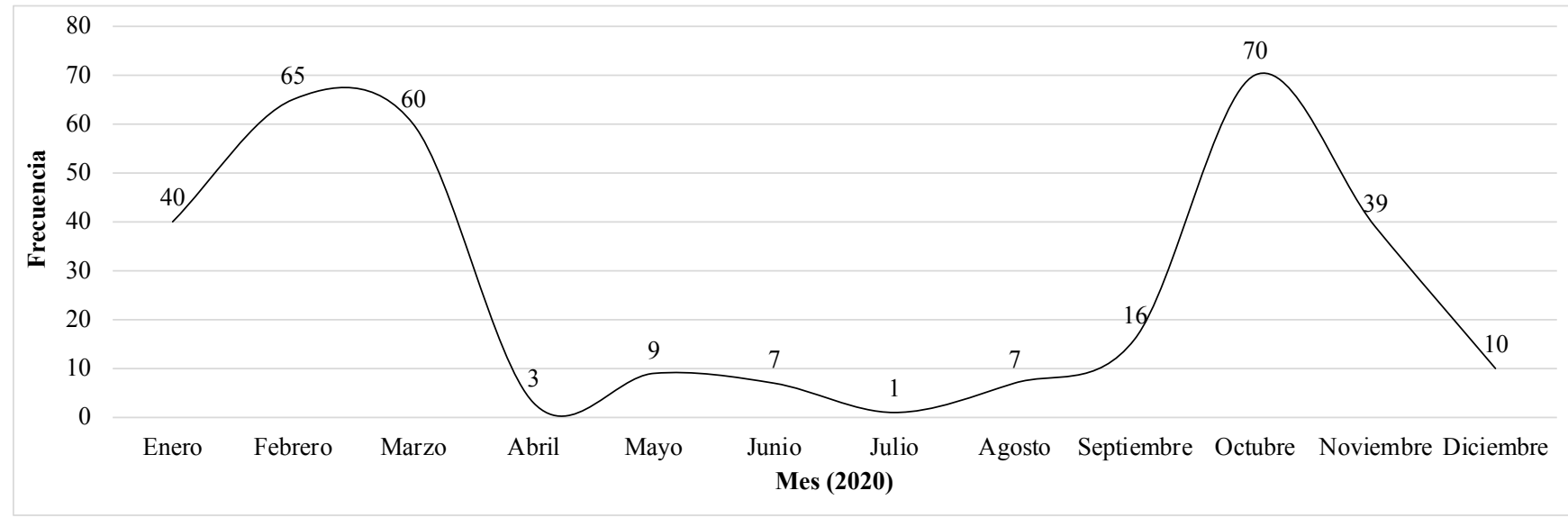

Fuente: elaboración propia con datos de las Casas de Asistencia para Migrantes (2020)

Esta frecuencia de menores en casas de los grupos migratorios son heterogéneos en los asistencia durante la contingencia de la que grupos minoritarios como los niños y niñas pandemia del Covid-19, permite evidenciar que se encuentran en condiciones de vulnerabilidad 
no sólo por las condiciones de seguridad como lo han reportado diversos estudios (Vargas-Orozco, et al., 2012; HernándezHernández, Vargas-Orozco y Villarreal-Sotelo, 2015), sino también por las condiciones de vulnerabilidad sanitaria con un alto riesgo de contagio de Covid-19. Esto queda evidenciado en el mismo proceso migratorio, al movilizar a esta población, muchas veces en grandes grupos, en condiciones de poca salubridad y sin las medidas de prevención de contagios de Covid-19 (OACNUDH, 2020a).

Con relación a los lugares de procedencia de las personas migrantes atendidas en las CAM, se identificó que el $88.1 \% \quad(n=3119)$ corresponde a migrantes nacionales, mientras que los internacionales tuvieron el $11.8 \%$ $(n=419)$. Respecto a los nacionales, se identificaron 10 estados de procedencia, siendo las personas migrantes del estado de Chiapas las que tuvieron una mayor frecuencia en la atención de las CAM ( $n=605,19.4 \%)$, mientras que los estados de Veracruz ( $n=389$, $12.5 \%)$, Michoacán $(n=382,12.2 \%)$, Tabasco $(n=369,11.8 \%)$ y Guerrero $(n=327,10.5 \%)$ tuvieron una frecuencia $>300$ personas cada uno durante el periodo de estudio, destacando que el $11.3 \%(n=351)$ de la población migrante atendida en las CAM es originaria del centro y sur del estado de Tamaulipas (Figura 6).

Figura 6. Estados de procedencia de personas migrantes atendidas durante el año 2020 por las casas de asistencia para migrantes en la ciudad de Reynosa, Tamaulipas

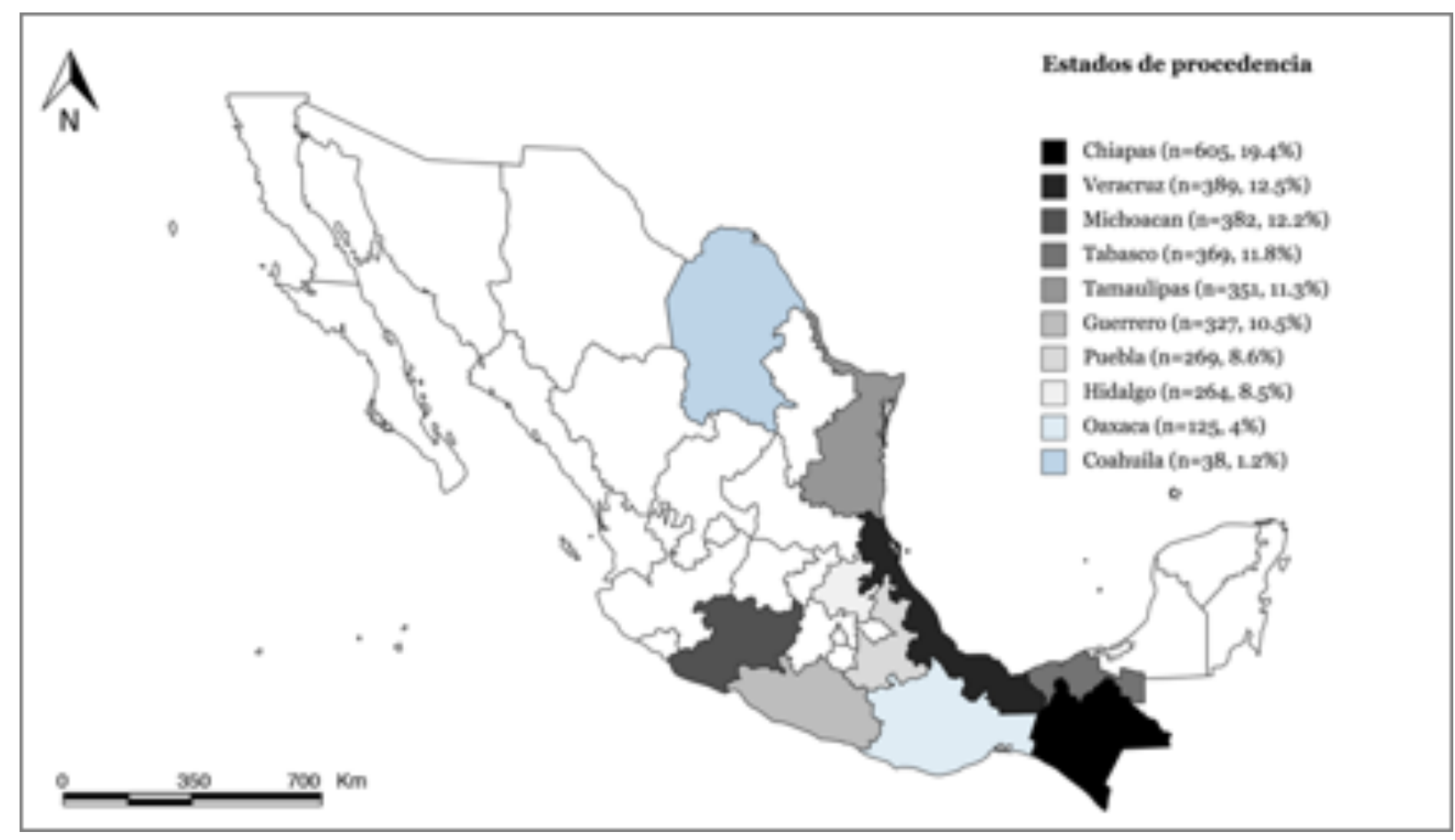

Fuente: elaboración propia con datos de las Casas de Asistencia para Migrantes (2020) 
De igual manera los estados como Puebla $(n=269,8.6 \%)$, Hidalgo $(n=264,8.5 \%)$, Oaxaca $(n=125,4 \%)$ y Coahuila $(n=38,1.2 \%)$ se caracterizan por tener una menor frecuencia de personas migrantes atendidas en las CAM; sin embargo, estas cifras permiten visibilizar que las CAM recibieron durante el año 2020 a personas migrantes del norte, centro y sur de México en un contexto de seguridad sanitaria global. La migración interna en México con destino a la frontera norte ha sido documentada como un fenómeno dinámico que ha ido en aumento en las últimas décadas (Rivera-Sánchez, 2017), ya que los flujos migratorios se han concentrado en la región noreste de México en los estados de Coahuila, Nuevo León, San Luis Potosí y en la región costera y fronteriza de Tamaulipas (Lomelí-Carrillo e Ybáñez-Zepeda, 2017).

La población migrante atendida en las CAM también estuvo integrada por personas de otros países. Se identificaron 419 personas migrantes (11.8\%) de 13 países de procedencia, de los cuales, 8 pertenecen a América Latina y el Caribe y 5 corresponden a la región de África Central y Occidental. México, además de ser un país emisor de migrantes mexicanos hacia Estados Unidos se ha convertido en un país de tránsito para migrantes (Pardinas, 2008), por lo que es común encontrar a personas de otros países en las principales zonas fronterizas del norte mexicano, generalmente en busca de mejores oportunidades en Estados Unidos o bien residiendo temporalmente en las ciudades mexicanas de la frontera (Carrasco-González, 2017).

La migración latinoamericana hacia Estados Unidos ha sido documentada como consecuencia de conflictos sociales, políticos, naturales y de seguridad, agravados por las condiciones de pobreza, principalmente en países centroamericanos como el Salvador, Nicaragua, Guatemala y Honduras (GonzálezReyes, 2009). El aumento de grupos de migrantes con destino a Estados Unidos en la última década ha provocado el endurecimiento de las políticas migratorias, provocando dos fenómenos de relevancia para las fronteras: 1) La presión política de Estados Unidos a México para limitar el ingreso de migrantes extranjeros al territorio mexicano con destino a Estados Unidos $^{3}$ y 2) el aumento de personas migrantes en las principales ciudades fronterizas tanto del norte como del sur de México.

La pandemia del Covid-19 trajo cambios en los procesos migratorios, ya que además provocó la respuesta de Estados Unidos ante la migración como un problema de seguridad nacional como dispersor de Covid-19 (International Crisis Group, 2020). Al respecto, durante el año 2020, las CAM recibieron de la región de América Latina a personas migrantes de Haití $(n=205,5.7 \%)$, Honduras $(n=111,3.1 \%)$ Guatemala $(n=48,1.3 \%)$, El Salvador $(n=40$, $1.1 \%)$, Chile $(n=3,0.08 \%)$, Venezuela $(n=3$, $0.08 \%)$, Cuba ( $n=2,0.06 \%$ ) y Brasil $(n=1,0.03 \%)$ (Figura 7), lo que coincide con lo reportado por

Este fenómeno es considerado en los estudios de migración como "tapón migratorio", se considera a México como un tapón migratorio junto con Marruecos y Turquía, ya que un país tapón es aquel con largas tradiciones migratorias pero se les ha impuesto (por Estados Unidos y la Unión Europea) el papel de puerta trasera para frenar migrantes (Varela-Huerta, 2016:41). 
Carrasco-González (2017) respecto a la región de Centroamérica y su alta frecuencia en las cifras de migración hacia el norte, con destino a
México o Estados Unidos (Castillo y Toussaint, 2015; Carrasco-González, 2017).

Figura 7. Países de procedencia de personas migrantes atendidas durante el año 2020 en las casas de asistencia para migrantes de la ciudad de Reynosa, Tamaulipas

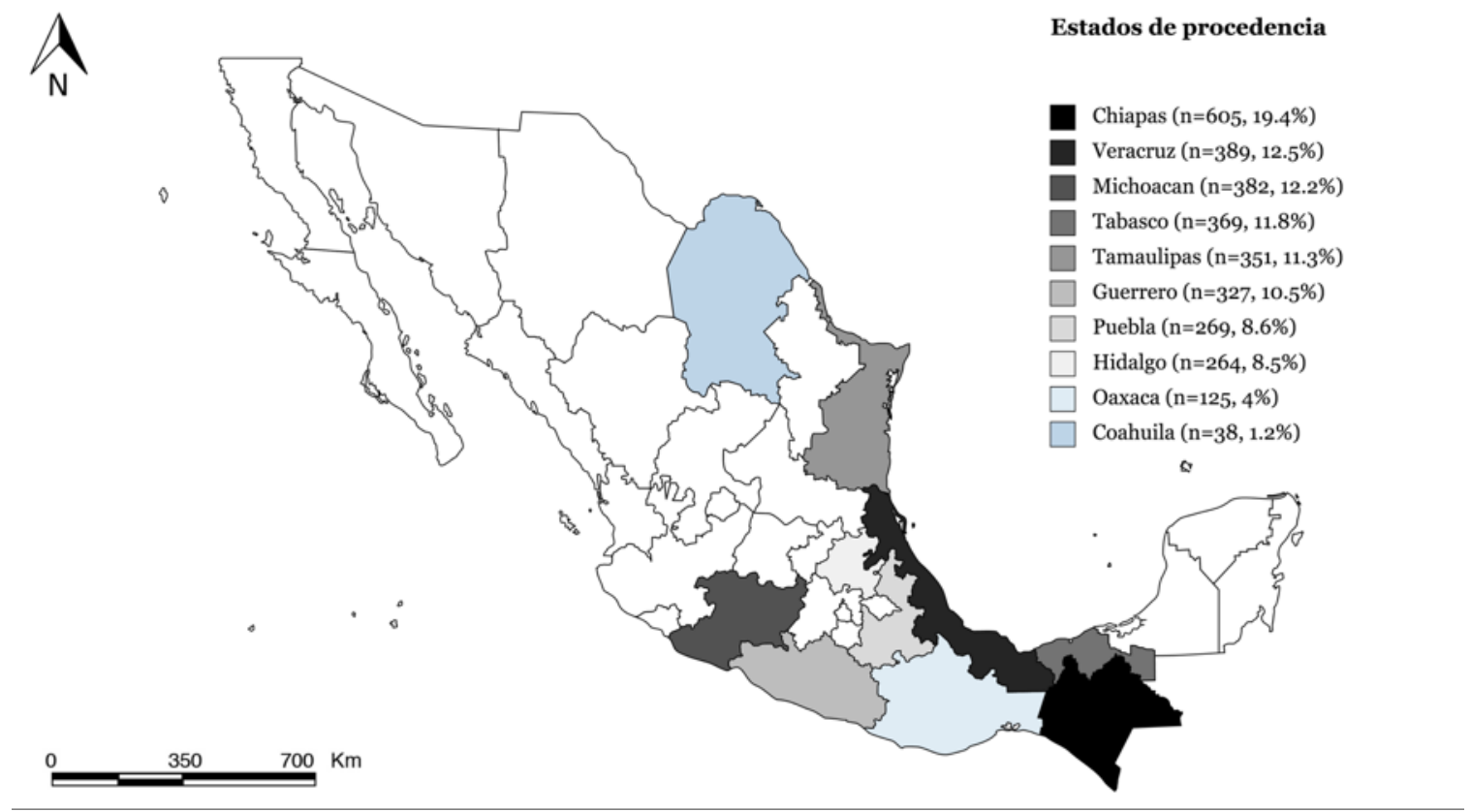

Fuente: elaboración propia con datos de las Casas de Asistencia para Migrantes (2020)

Los migrantes procedentes de Haití ocuparon el segundo país de origen de las personas atendidas en las CAM (Figura 7), lo cual, está relacionado a la reciente oleada de personas de este país con destino a México y Estados Unidos, iniciada en el periodo 2016 hasta el segundo semestre de 2018, con destino a las principales ciudades del centro del país y de la frontera norte (MontoyaOrtiz y Sandoval-Forero, 2018) buscando asilo político o bien llegando de manera ilegal en busca de mejores oportunidades de desarrollo (Félix-Vega y París-Pombo, 2018).

De la región de África Central eran originarios de Camerún ( $n=1,0.03 \%)$, Burundi $(n=1,0.03 \%)$ y la República Democrática del Congo $(n=1$, $0.03 \%)$, mientras que de la región de África Occidental pertenecían a países como Guinea $(n=2,0.06 \%)$ y Costa de Marfil $(n=1,0.03 \%)$. La migración de extranjeros de origen africano se ha incrementado en la última década (EscrichGallardo, 2018), esta población principalmente ingresa por la frontera sur de México y tiene como destino la frontera norte, con el objetivo de solicitar visas temporales o asilo político a Estados Unidos; sin embargo, a partir de 2016, disminuyó la atención en las oficinas de inmigración de Estados Unidos, reduciendo el número de atenciones de 70 solicitudes de visa o asilo por día antes de 2016, hasta 20 
solicitudes o ninguna por día durante 2017 (Consejo Ciudadano del Instituto Nacional de Migración, CCINM, 2017), lo que ha derivado en que estas personas permanezcan en la zona fronteriza mexicana en espera de atención por parte de las autoridades estadounidenses.

Las principales desafíos del proceso migratorio que han sido documentados, tanto para migrantes nacionales como extranjeros, son las condiciones de inseguridad en la región norte de México derivadas de los conflictos contra el narcotráfico por parte del gobierno mexicano y entre los grupos criminales de la región (González-Reyes, 2009; Ybáñez-Zepeda y Alarcón, 2014; Correa-Cabrera, 2016; CastilloRamírez, 2020), además, otro de los principales obstáculos de la migración extranjera son las barreras lingüísticas y culturales (CCINM, 2017), ya que en el caso de los migrantes de África atendidos por las CAM, los idiomas son tan heterogéneos como sus lugares de origen, de manera que en la República Democrática del Congo el idioma oficial es el francés, en Camerún el francés e inglés, en Burundi el francés, inglés y kirundi, en Guinea es el español, francés y portugués y en Costa de Marfil el francés.

Esta condición de diferencias lingüísticas limita o reduce el acceso a servicios de representación institucional en las fronteras, principalmente los servicios de asistencia jurídica que no cuentan con personal que hablen el mismo idioma que las personas migrantes (CCINM, 2017), al igual que para acceder a trabajo temporal en la frontera o bien para servicios médicos. En este sentido, además de estas condiciones de vulnerabilidad que han caracterizado la migración en el norte de
México, la situación de vulnerabilidad sanitaria en la población migrante sigue presente, ya que de los 16 migrantes contagiados de Covid-19 en una CAM en el municipio de Nuevo Laredo Tamaulipas, 11 eran extranjeros, provenientes de Honduras $(n=6)$, Cuba $(n=3)$, Guatemala $(n=1)$ y de Camerún $(n=1)$; mientras que 4 eran de nacionalidad mexicana y uno sin identificar su nacionalidad (Gobierno de Tamaulipas, 2020). Por lo anterior la afluencia de personas migrantes en la frontera norte de Tamaulipas, requiere la implementación de políticas públicas para la atención gubernamental de este grupo social también en el contexto de la pandemia del Covid-19.

En cuanto a las enfermedades y padecimientos médicos en esta población de estudio, se identificó que las personas migrantes fueron atendidas por el personal de las CAM en el suministro de medicamentos y consultas médicas, en primer lugar (en orden defrecuencia) (Figura 8), las enfermedades respiratorias $(n=9)$ se reportaron en los meses correspondientes a la temporada invernal (noviembre-enero), mientras que las enfermedades digestivas $(n=7)$ fueron reportadas en el periodo julio-octubre, las cuales, pueden estar relacionadas al aumento de la temperatura en la región y el consumo de alimentos frescos o bien a la diferencia alimentaria. Los padecimientos musculares $(n=6)$ se registraron en los meses de marzo y agosto, y junto con los traumas físicos $(n=3)$ pueden estar relacionados a las actividades laborales que desempeñan los migrantes para obtener ingresos económicos ya que, generalmente, realizan trabajos de albañilería y construcción, mecánica automotriz y trabajos agrícolas. 
Figura 8. Enfermedades y padecimientos médicos atendidos por las casas de asistencia para migrantes de Reynosa, Tamaulipas durante 2020

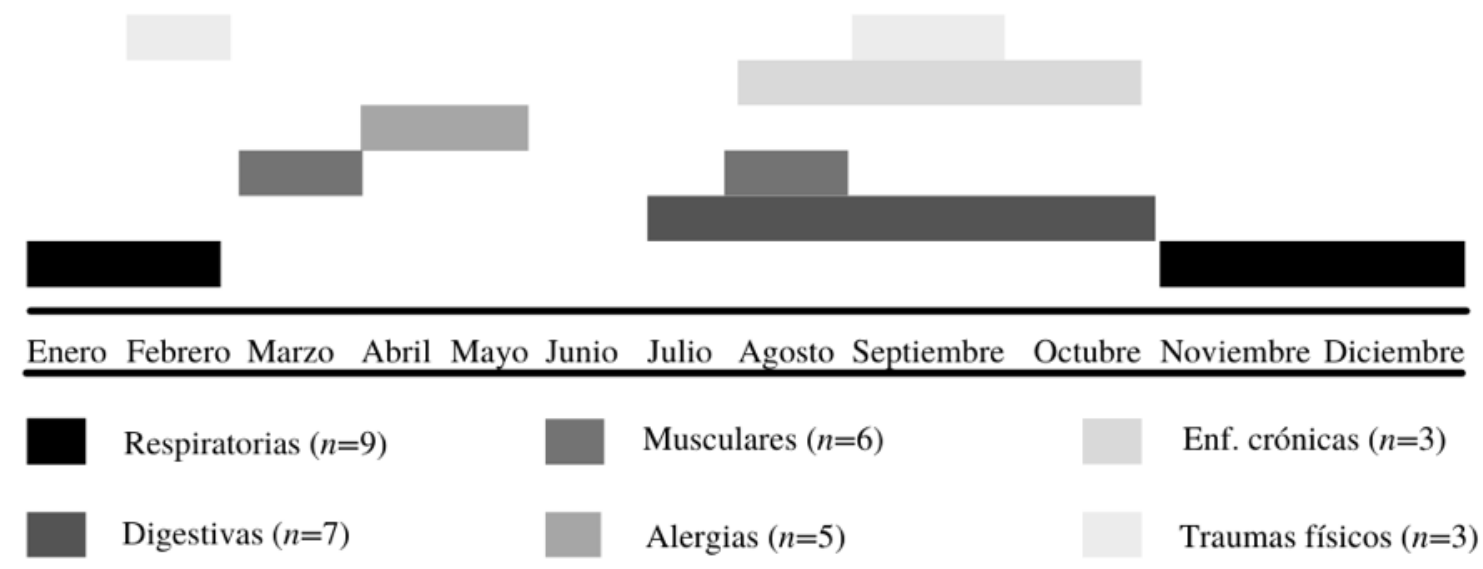

Fuente: Elaboración propia

Respecto a las alergias, los casos reportados $(n=5)$, muestran que fueron atendidos en los meses de abril y mayo y por último, las enfermedades crónicas $(n=3)$ estuvieron representadas por personas que padecen diabetes mellitus. Estos padecimientos fueron atendidos por los servicios médicos de consulta y medicamento de las CAM, las cuales, reciben donaciones de medicamentos y servicio social por parte de médicos voluntarios. Esto anterior permite establecer que las personas migrantes reciben atención médica de acuerdo a sus capacidades, ya que en los casos cuando se requieren servicios médicos especializados, el Instituto Tamaulipeco para los Migrantes apoya a las CAM para facilitar la gestión administrativa y financiera de estos servicios.

\subsection{Estrategias y desafíos ante la pandemia del Covid-19}

La pandemia del coronavirus (Covid-19) tuvo serios impactos en el funcionamiento de las
Casas de Asistencia para Migrantes (CAM), si bien, porque las medidas de prevención de contagios estaban fundamentadas en el aislamiento social y la seguridad sanitaria, mientras que el objetivo de las CAM es la atención de un gran número de personas en condiciones de vulnerabilidad social, por lo que están adaptadas para atender este tipo de fenómenos (seguridad, hospedaje, transporte, alimentación, vinculación, etc.).

Sin embargo, la pandemia llevó a estas instituciones a desarrollar estrategias de prevención y atención frente a nuevos retos y desafíos de carácter sanitario para atender al mayor número de personas garantizando la protección sanitaria tanto de personas migrantes como del personal de las CAM y fundamentadas en los derechos humanos de las personas en migración. A continuación se analizan los principales retos y desafíos que enfrentaron las CAM para atender a este grupos social en el contexto de la pandemia, así como 
de las principales estrategias para lograr la seguridad sanitaria.

\subsection{Retos y desafíos para la prevención de contagios de Covid-19 en migrantes}

Respecto a los principales retos y desafíos de las CAM se identificaron dos fenómenos de interés: a) la falta de información y escepticismo respecto a la pandemia y sus formas de contagio $y$ b) las dificultades económicas dentro de las CAM.

\section{a) Falta de Información y escepticismo}

Se destaca que la falta de información y la incredulidad por parte de la población respecto al Covid-19, tuvo un papel fundamental en la epidemiologia del coronavirus a nivel global (Bisso-Andrade, 2020). Este fenómeno ha sido reportado y documentado no sólo en la frontera, sino en otros lugares del centro de México (Trujillo-Pérez, 2020), y Latinoamérica como Paraguay (Florentín, Maldonado y Portillo, 2020) y El Salvador (Martínez-Jurado y Meléndez-Alfaro, 2020).

En el caso de las CAM, reportaron que esto implicó un desafío para garantizar la seguridad de las personas migrantes y del personal de atención, ya que al principio de la contingencia sanitaria, diversas personas se resistían a usar el material de protección personal como los cubrebocas, el gel antibacterial, etc., por escepticismo frente a la existencia del coronavirus y a las formas de contagio.

Lo que nos afectó al principio fue la falta de información de lo que era la pandemia y el coronavirus, porque algunos [migrantes] se resistían a cumplir con las indicaciones sanitarias que les dábamos aquí en la casa por lo que teníamos que estar informando [sobre el coronavirus] a los que iban Ilegando (Comunicación personal, ANSG, 3 de enero de 2021)

El fenómeno del escepticismo y la falta de información tienen serias implicaciones a nivel epidemiológico, lo que deriva en que las personas no tomen las medidas preventivas necesarias pudiendo generar contagios masivos $y$ descontrolados (Florentín, Maldonado y Portillo, 2020:21) y que están fundamentados en la mala administración gubernamental de los Estados, las noticias falsas (fake news) y a la desinformación en general (Bisso-Andrade, 2020; MartínezJurado y Meléndez-Alfaro, 2020).

\section{b) Las dificultades económicas}

Respecto a las condiciones económicas dentro de las CAM, es necesario mencionar que el impacto de la pandemia ha afectado negativamente a la economía global, ya que esta emergencia sanitaria implicó un choque económico tanto de oferta como de demanda (Clavellina-Miller y Domínguez-Rivas, 2020). Entre las principales afectaciones económicas provocadas por la pandemia, fue el cierre temporal y/o definitivo de pequeñas y medianas empresas (García-Muñoz, Pérez-Sánchez y Navarrete-Torres, 2020), situación que no fue ajena a las CAM, ya que una de las principales fuentes de abastecimiento de alimentos y recursos provienen de las tiendas locales de la región. 
Con la cuarentena se retiraron los donadores de alimento, muchos negocios [tiendas] dejaron de donarnos comida porque ellos también se encontraban cerrados por la pandemia por lo que no tenían cómo ayudarnos, además, las personas de otras comunidades religiosas, principalmente de otras parroquias y otros voluntarios dejaron de alimentar a los migrantes en la calle por miedo a contagiarse, por lo que a nosotros se nos incrementó el consumo de comida (Comunicación personal, ANSG, 3 de enero de 2021)

Además de las necesidades de básicas para la atención de migrantes en las CAM, la pandemia de la Covid-19 implicó gastos económicos en otros insumos propios de la emergencia sanitaria, la adaptación de los espacios dentro de las CAM para mantener la distancia, los consumibles de seguridad personal como los cubrebocas y guantes (generalmente de un solo uso) y el alto flujo de personas, provocaron gastos económicos considerables, aunado al retiro de los apoyos de las empresas y otras organizaciones no gubernamentales locales.

Nos falta apoyo económico para el mantenimiento y adaptación del lugar, así como del equipo para migrantes sospechosos de Covid-19, para poder aislarlos de los demás [...] le hemos hecho como podemos para garantizar que todos estén a salvo, pero sin equipo es más difícil (Comunicación personal, ANSG, 3 de enero de 2021)

Necesitamos consolidar los equipos de terapia respiratoria para adultos y niños en caso de que llegáramos a necesitar, así como de un mayor suministro de cubrebocas, mascarillas y kit personal de aseo (Comunicación personal, ASDV, 4 de enero de 2021)

Estas afectaciones a las CAM permite visibilizar el contexto bajo el cual, se desarrolló la atención de personas migrantes durante la pandemia y de cómo estas instituciones han enfrentado el desafío de atender a un gran número de personas en condiciones de vulnerabilidad social y sanitaria en la frontera norte de Tamaulipas.

\subsection{Estrategias de prevención de contagios durante la emergencia sanitaria.}

Las CAM enfrentaron este escenario de la pandemia de la Covid-19 a través de estrategias decolaboración interinstitucional, con el objetivo de garantizar la menor cantidad de contagios de coronavirus en la población migrante atendida. Destacando que el principal objetivo dentro de las CAM durante la contingencia es mantener segura a la población migrante, tal como lo afirman el personal de la casa: "Nuestro principal reto es mantener la meta de cero contagios o infecciones en la casa" (Comunicación personal, ASDV, 4 de enero de 2021)

En este sentido, las medidas de seguridad en las CAM fueron adoptadas de las disposiciones de la Secretaria Salud y de la Organización Mundial de la Salud (2020b), respecto al uso de cubrebocas, el distanciamiento físico, el lavado constante de manos y la revisión constante de la temperatura.

Al igual que otros establecimientos, les solicitamos [a los migrantes y el personal de 
la CAM] el uso correcto y constante de los cubrebocas así como el lavado de manos, la toma de temperatura al ingresar a la casa y el distanciamiento social, que incluso fue en los dormitorios, por lo que habilitáramos otras áreas de la casa como dormitorio. Además procuramos la sanitización del albergue dos veces al día (Comunicación personal, ANSG, 3 de enero de 2021)

Además de la sanitización normal como el uso de cubrebocas, tapetes para el calzado, uso de gel antibacterial, lavado de manos constante, etc. Limpiamos la cuadras [término para designar las distintas áreas de la casa] con aerosoles y detergente (Comunicación personal, ASDV, 4 de enero de 2021)

Esta adaptación de los espacios, permitió que las personas migrantes dentro de las casas tuvieran espacios suficientes para distribuir a las personas garantizando la distancia física, además la sanitización constante de los espacios ha permitido reducir el riesgo de contagios dentro de las CAM.

\section{a) El apoyo médico}

Con relación a la colaboración interinstitucional, el apoyo por parte de Médicos Sin Fronteras", la Secretaria de Salud del estado de Tamaulipas

4 Médicos Sin Fronteras (MSF) es una organización que trabaja para mejorar el acceso a la atención médica y psicológica también para población migrante y refugiada ofreciendo servicios médicos de calidad y atención a la salud mental. Ofrece sus servicios en la ruta migrante como en Tenosique (Tabasco), en Coatzacoalcos (Veracruz), y en Reynosa, Matamoros (Tamaulipas) (Médicos Sin fronteras, 2021) y la Cruz Roja permitió la atención medica de calidad para personas migrantes en las CAM durante la pandemia. Ya que se implementaron protocolos de atención continua a las personas migrantes dentro de las casas, con el objetivo de monitorear a la población para la identificación oportuna de casos.

Implementamos la revisión médica de las personas todos los días, es decir, la asistencia médica es a diario para identificar posibles síntomas en algún migrante y así poder reaccionar ante un posible contagio dentro de la casa, quien nos ha auxiliado con eso es Médicos Sin fronteras, la Secretaria de Salud del Estado y la Cruz Roja (Comunicación personal, ANSG, 3 de enero de 2021)

El apoyo de Médicos Sin Fronteras y de la Secretaria de Salud del Estado y la Cruz Roja ha sido muy importante para nosotros, ya que gracias a ellos podemos darle a las personas migrantes una atención permanente $y$ revisiones periódicas del estado de salud de cada uno de ellos (Comunicación personal, ASDV, 4 de enero de 2021)

En este sentido, la colaboración por parte de las CAM con otros organizaciones no gubernamentales como Médicos Sin Fronteras y las instituciones de gobierno Estatal y Federal han permitido que, en gran medida, las personas migrantes tengan acceso a un ambiente seguro para residir en la frontera norte del estado de Tamaulipas en su trayecto migratorio. 


\section{CONCLUSIONES}

La pandemia por Covid-19 ha tenido profundos impactos en los procesos migratorios, y las casas de asistencia para migrantes se han enfrentado a un contexto de emergencia sanitaria nunca registrada en épocas recientes y sin protocolos para la atención de grandes grupos sociales como lo es la población migrante. Además, como se evidenció a lo largo del presente estudio, las casas de asistencia para migrantes en la frontera norte de Tamaulipas, México, atendieron a una considerable cantidad de personas migrantes, garantizando el hospedaje, alimentación, atención médica y seguridad de mujeres, hombres, niñas y niños.

Se concluye que las casas de asistencia para migrantes son instituciones que han sido fundamentales para el proceso migratorio y a su vez representan, durante el periodo de pandemia, un lugar de cobijo y seguridad para esta población vulnerable, destacando su capacidad para adaptarse a nuevos contextos socio-sanitarios y la capacidad de colaboración para la protección de los derechos fundamentales de las personas migrantes nacionales e internacionales.

Queda pendiente analizar cómo se estructuran las redes de apoyo médico, económico, de alimentación y sanitario de las casas de asistencia para migrantes en el contexto de la pandemia del coronavirus (Covid-19), así como de las respuestas gubernamentales en la implementación de políticas públicas en materia de salud y migración para garantizar la seguridad sanitaria de personas que van de paso o de retorno por las fronteras del norte de
México, en especial por la frontera norte del estado de Tamaulipas.

\section{TRABAJOS CITADOS}

Alba, Francisco. (1979). La población de México, evoluciones y dilemas. México: El Colegio de México

Barrón, Martín. (2013). La Bestia: La tenue línea entre la migración y la trata de personas. México: INACIPE.

Bericat, Eduardo. (1998). Estrategias y usos de la integración. En Bericat Eduardo (Ed.) La integración de los métodos cuantitativo y cualitativo en la investigación social, significado y medida. España: Editorial Ariel. Recuperado de http://mastor.cl/blog/wp-content/uploads/2019/07/ Bericat-La-Integracion-de-Los-Metodos-Cuanti-y-Cuali.pdf

Bryman, Alan. (2006). Integrating quantitative and qualitative research: how is it done? Qualitative Research. Vol. 6(1):97113. Recuperado de https://people.utm.my/uzairiah/wpcontent/blogs.dir/1541/files/2016/11/Qualitative-Research2006-Bryman-97-113.pdf

Carpio-Domínguez, José., Vargas-Orozco, Cynthia., Hernández-Rodríguez, Ignacio y Villarreal-Sotelo, Karla. (2017). La vida carcelaria de los migrantes extranjeros en Reynosa, Tamaulipas, México. Perspectivas Sociales, Vol. 19(2): 89-107. Recuperado de http://perspectivassociales. uanl.mx/index.php/pers/article/view/16/12

Carrasco-González, Gonzalo. (2017). La migración centroamericana en su tránsito por México hacia los Estados Unidos. Alegatos. Año 32 (97): 169-194. Recuperado de http://revistastmp.azc.uam.mx/alegatos/index.php/ra/ article/view/187

Castillo-Ramírez, Guillermo. (2020). Migración forzada y procesos de violencia: Los migrantes centroamericanos en su paso por México. Revista Española de educación Comparada. No. 35: 14-33. Recuperado de https:// www.comecso.com/wp-content/uploads/2021/01/ Migracio\%CC\%81n-forzada-y-procesos-de-violencia.pdf

Castillo, Manuel y Toussaint, Mónica. (2015). La frontera sur de México: orígenes y desarrollo de la migración 
centroamericana. Cuadernos Inter-c-a-mbio sobre Centroamérica y el Caribe. Vol. 12(2): 59-86. https://www. redalyc.org/pdf/4769/476947244004.pdf

Consejo Ciudadano del Instituto Nacional de Migración,CCINM- (2017). Grupos de Trabajo: Repatriaciones / Visas por razones humanitarias. Caso: Haitianos y Africanos en la Frontera Norte de México. Gobierno de México. Recuperado de https://www.gob.mx/cms/uploads/attachment/ file/281220/Informe_Caso_Haitianos_y_Africanos.pdf

Correa-Cabrera, Guadalupe. (2016). Militarización y violencia en Tamaulipas. En Armando Rodríguez y Sergio Aguayo (Eds.) Atlas de la Seguridad y la Defensa de México (pp. 181-190). México: Colectivo de Análisis de la Seguridad con Democracia (CASEDE). Recuperado de https://www. casede.org/index.php/publicaciones/atlas-de-la-seguridady-la-defensa-de-mexico-2016\#: :text=El\%20Atlas\%20 de $\% 20$ la $\% 20$ Seguridad,los $\% 20$ derechos $\% 20$ humanos $\% 20$ en $\% 20 M \% C 3 \%$ A9xico.

Creswell, John. (2008). Mapping the field of mixed methods research. Journal of Mixed Methods Research. Vol. 3(2): 95108. https://doi.org/10.1177/1558689808330883

D’Souza, Deena., Quadros, Shalini., Hyderabadwala, Zainab. \& Mamun, Mohammed. (2020). Aggregate COVID-19 suicide incidences in India: Fear of COVID-19 infection is the prominent causative factor. Psychiatry Research. 290: 113145. DOI: 10.1016 / j.psychres.2020.113145

Escrich-Gallardo, Teresa. (2018). Migración y Desarrollo. Refugiados africanos en México. Un análisis desde el interculturalismo y el Enfoque Basado en Derechos. México: Ed. Sin Fronteras. Recuperado de https://sinfronteras.org. mx/wp-content/uploads/2018/12/africanos-2013.pdf

Félix-Vega, Carlos y París-Pombo, María. (2018). Características sociodemográficas, salud y oportunidades de empleo: Resultados de la Encuesta a Migrantes Extranjeros Albergados en Tijuana El Colef-CNDH 2017. En ParísPombo, María (Coord.) Informe Especial Migrantes Haitianos y Centroamericanos en Tijuana, Baja California 2016-2017. Políticas gubernamentales y acciones de la sociedad civil (pp. 35-56). México: Colegio de la Frontera
Norte. Recuperado de https://www.cndh.org.mx/sites/all/ doc/Informes/Especiales/Informe-Migrantes-2016-2017.pdf

Gobierno de México (2020a). Acuerdo por el que se declara como emergencia sanitaria por causa de fuerza mayor, a la epidemia de enfermedad generada por el virus SARSCov2 (COVID-19). Diario Oficial Federal, 30 de marzo. Recuperado de: https://www.dof.gob.mx/nota_detalle. php?codigo $=5590745 \&$ fecha $=30 / 03 / 2020$

Gobierno de México (2020b). Estadísticas migratorias, Síntesis 2020. Unidad de política migratoria, registro e identidad de personas y Subsecretaría de Derechos Humanos, Población y Migración. Recuperado de http://portales.segob.gob.mx/ work/models/PoliticaMigratoria/CEM/Estadisticas/Sintesis_ Graficas/Sintesis_2020.pdf

Gobierno del Estado de Tamaulipas (20 de abril 2020). Confirma secretaria de Salud de Tamaulipas 16 casos de migrantes con Covid-19. Recuperado de: https://www.tamaulipas.gob.mx/ haciendoequipo/2020/04/20/confirma-secretaria-de-saludde-tamaulipas-16-casos-de-migrantes-con-covid-19/

Gobierno del Estado de Tamaulipas (2020). DECRETO Gubernamental mediante el cual se dictan medidas de seguridad sanitaria para combatir la enfermedad grave de atención prioritaria generada por el VIRUS SARS-COV2 (Covid-19) en el Estado Libre y Soberano de Tamaulipas. Periódico Oficial del Estado de Tamaulipas 29 de marzo de 2020. Recuperado de https://coronavirus.tamaulipas.gob. mx/wp-content/uploads/sites/104/2020/10/cxlv-ext.num02-290320f-1.pdf

Gómez-Walteros, Jaime. (2010). La migración internacional: teorías y enfoques, una mirada actual. Revista Semestre Económico. Vol. 13(26):81-99. Recuperado de https://www. redalyc.org/pdf/1650/165014341004.pdf

González-Reyes, Jesús. (2009). Migración, criminalidad y violencia en la frontera norte de México. Revista Criminalidad. Vol. 51(2): 47-60. Recuperado de http://www. scielo.org.co/pdf/crim/v51n2/v51n2a04.pdf

Greene, Jennifer., Caracelli, Valerie \& Graham, Wendy. (1989). Toward a conceptual framework for mixed- 
method evaluation designs. Educational Evaluation and Policy Analysis. Vol. 11(3): 255-274. DOI: https://doi. org/10.3102/01623737011003255

Griffiths, Mark. \& Mamun, Mohammed. (2020). Covid-19 suicidal behavior among couples and suicide pacts: Case study evidence from press reports. Psychiatry Research. Vol. 289:113105. Recuperado de 10.1016/ j.psychres.2020.113105

Hernández-Hernández, O. (2021). Organizaciones gubernamentales, no gubernamentales y atención a migrantes en Tamaulipas, México en tiempos de Covid-19. Ciencia y Sociedad, 46(2): 65-83. doi: https://doi. org/10.22206/cys.2021.v46i2

Hernández-Hernández, Oscar., Vargas-Orozco, Cynthia y Villarreal-Sotelo, Karla. (2015). Migración y repatriación de menores por la frontera Tamaulipas-Tamaulipas. México: Universidad Autónoma de Tamaulipas. Recuperado de https://www.colef.mx/noticia/libro-migracion-yrepatriacion-de-menores-por-la-frontera-tamaulipas-texas/ International Crisis Group (2020). Deportación y enfermedad: los dilemas del COVID-19 en Centroamérica. Recuperado de https://www.crisisgroup.org/latin-america-caribbean/ central-america/guatemala/deportation-and-diseasecentral-americas-covid-19-dilemmas

Izcara-Palacios, Simón y Andrade-Rubio, Karla. (2015). Causas e impactos de la deportación de migrantes centroamericanos de Estados Unidos a México. Estudios Fronterizos. Vol. 16(31): 239-271. Recuperado de http://www.scielo.org.mx/ pdf/estfro/v16n31/v16n31a10.pdf

Izcara-Palacios, Simón. (2012). Violencia contra inmigrantes en Tamaulipas. European Review of Latin American and Caribbean Studies, No. 93: 3-24. Recuperado de https:// www.jstor.org/stable/23294468?seq=1

Lomelí-Carrillo, Uriel e Ybáñez-Zepeda, Elmyra. (2017). Los flujos de migración interna a través del análisis de redes: Comparación entre dos regiones fronterizas de México, 1995 y 2015. Revista Frontera Norte. Vol. 29(58): 95120. Recuperado de http://www.scielo.org.mx/pdf/fn/ v29n58/0187-7372-fn-29-58-00095.pdf
Macintosh, Kenneth. (2020). Coronavirus disease 2019 (COVID-19): Epidemiology, virology, and prevention. UpToDate. Recuperado de https://www.uptodate. com/contents/coronavirus-disease-2019-covid-19epidemiology-virology-and-prevention

Montoya-Ortiz, Merari. y Sandoval-Forero, Eduardo. (2018). Migrantes haitianos en México: un nuevo escenario migratorio. Huellas de la Migración. Año 3(6): 133-156. Recuperado de https://huellasdelamigracion.uaemex.mx/ article/view/11719/9430

Oficina de Alto Comisionado de las Naciones Unidas para los Derechos Humanos -OACNUDH- América Central, Oficina Regional (2020a). Los derechos a la salud de las personas refugiadas, migrantes y apátridas deben ser protegidos en la respuesta ante COVID-19: Comunicado conjunto de ACNUIR, OIM, OACNUDH y OMS. Recuperado de: http://www.oacnudh.org/los-derechos-a-la-salud-de-laspersonas-refugiadas-migrantes-y-apatridas-deben-serprotegidos-en-la-respuesta-ante-covid-19-comunicadoconjunto-de-acnur-oim-oacnudh-y-ops/

Oficina de Alto Comisionado de las Naciones Unidas para los Derechos Humanos -OACNUDH- (2020b). Directrices relativas a la COVID-19. 8 de mayo de 2020. Recuperado de: https://www.ohchr.org/SP/NewsEvents/Pages/ COVID19Guidance.aspx

Oficina de Alto Comisionado de las Naciones Unidas para los Derechos Humanos -ACNUDH- (2020c). Directrices esenciales para incorporar la perspectiva de derechos humanos en la atención a la pandemia por COVID-19. 12 de mayo 2020 Recuperado de: http://www.oacnudh.org/ wp-content/uploads/2020/05/V1.6_Directrices_ONU-DH_ Covid19_y_Derechos_Humanos_ROCA.pdf

Oficina de Alto Comisionado de las Naciones Unidas para los Derechos Humanos -ACNUDH- (2020d). COVID-19 y los Derechos Humanos de los Migrantes: Guía. 7 de abril 2020. Recuperado de: https://www.ohchr.org/Documents/Issues/ Migration/OHCHRGuidance_COVID19_Migrants_sp.pdf Organización Internacional para las Migraciones- OIM(2020). Informe sobre las migraciones en el mundo 2020. 
Organización de las Naciones Unidas. Recuperado de https://publications.iom.int/system/files/pdf/wmr_2020_ es.pdf

Organización Mundial de la Salud -OMS- (2020). Alocución de apertura del Director General de la OMS en la rueda de prensa sobre la COVID-19 celebrada el 11 de marzo de 2020. Recuperado de: https://www.who.int/es/ director-general/speeches/detail/who-director-general-sopening-remarks-at-the-media-briefing-on-covid-19---11march-2020

Organización Mundial de la Salud -OMS- (2020b). Brote de enfermedad por coronavirus (COVID-19): orientaciones para el público. Recuperado de https://www.who.int/es/ emergencies/diseases/novel-coronavirus-2019/advice-forpublic?gclid=CjwKCAiAp4KCBhB6EiwAxRxbpKL8DZjEB cE-5GQotbQxUeLqDdO4IfHysgskRhhNs4j6P8J9DsxVqxo CMiYQAvD_BwE

Palacios-Cruz, M., Santos, E., Velázquez-Cervantes, M. y León-Juárez, M. (2020). COVID-19, una emergencia de salud pública mundial. Revista Clínica Española. S0014-2565(20)30092-8. DOI: https://doi.org/10.1016/j. rce.2020.03.001

Riggirozzi, Pía., Grugel, Jean y Cintra, Natalia. (2020). Reporte situacional: perspectivas sobre el derecho a la salud de los migrantes en América Latina durante Covid-19. Lancet Migration. Recuperado de https://1bec58c3-8dcb46b0-bb2a-fd4addf0b29a.filesusr.com/ugd/188e74_ c6d657a05e0c46758c8052542c71e4e1.pdf

Rivera-Sánchez, Liliana. (2017). De la migración interna a la migración internacional en México. Apuntes sobre la formación de un campo de estudio. Íconos, Revista de Ciencias Sociales. No. 58: 37-57. DOI: https://doi. org/10.17141/iconos.58.2017.2500

Secretaría de Salud (2020). Acuerdo por el que se establecen acciones extraordinarias para atender la emergencia sanitaria generada por el virus SARS-CoV2. Diario Oficial de la Federación 31 de marzo de 2020. Gobierno de México. Recuperado de https://www.dof.gob.mx/nota_detalle. php?codigo $=5590914 \&$ fecha $=31 / 03 / 2020 \&$ print $=$ true
Sedas, Ana., Aguerrebere, Mercedes., Martínez-Juárez, Luis., Zavala-de Alba, Luis., Egiluz, Itzel. y Bhabha, Jacqueline. (2020). Reporte situacional: situación de tránsito en México durante la pandemia de Covid-19. Lancet Migration. Recuperado de https://1bec58c38 d c b- 46 b 0 - b b 2 a - fd 4 addf0b 29 a.filesusr.com/ ugd/188e74_16722de523 cb4f12a0901f79e4db8cbc. pdf?index=true

Sher, Leo. (2020). The impact of the COVID-19 pandemic on suicide rate. QJM: An International Journal of Medicine. Vol. 113(10): 707-712. DOI: https://doi.org/10.1093/qjmed/ hcaa202

Torok, Michelle. (2002). Epidemic Curves Ahead. Focus on Field Epidemiology. Vol. 1(5): 1-5. Recuperado de https:// nciph.sph.unc.edu/focus/vol1/issue5/1-5EpiCurves_ issue.pdf?_ga=2.60224045.1850820335.16140405821437409862.1614040582

Varela-Huerta, Amartela. (2016). Luchas migrantes en contextos de tránsito migratorio, el caso del movimiento migrante centroamericano. Revista Interdisciplinar da Movilidade Humana. Vol. 24(48): 31-44. Recuperado de https://www.scielo.br/pdf/remhu/v24n48/1980-8585REMHU-24-48-031.pdf

Vargas-Orozco, Cynthia., Arrona-palacios, Arturo., VillarrealSotelo, Karla., Sánchez-Vázquez, Rafael y GorjónGómez, Francisco. (2015). Menores migrantes repatriados no acompañados en Reynosa, Tamaulipas: un análisis descriptivo del flujo migratorio. Revista Ciencia UAT. Vol. 6(3): 6-13. Recuperado de https://www.redalyc.org/ pdf/4419/441942927003.pdf

Ybáñez-Zepeda, Elmyra y Alarcón, Rafael. (2014). Turbulencia económica, violencia y cambios migratorios en la frontera norte de México, 1990-2010. Migración y Desarrollo. No. 22: 61-90. Recuperado de http://www.scielo.org.mx/pdf/ myd/v12n22/v12n22a3.pdf

Zhou, Peng., Yang, Xing., Wang, Xian., Hu, Ben., Zhang, Lei., Zhang, wei., Si, Hao., Zhu, Yan., Li, Bei., Huang, Chao., Chen, Hiu., Chen, Jing., Loui, Yun., Guo, Hua., Jiang, Ren., Lui,, Mei., Chen, Ying., Shen, Xu., Wang, Xi., Zheng, Xiao., 
Zhao, Kai., Chen, Quan., Deng, Fei., Liu, Lin., Yan, Bing., Zhan, Fa., Wang, Yan., Xiao, Geng., Shi, Zheng. (2020). A pneumonia outbreak associated with a new coronavirus of probable bat origin. Nature. No. 579: 270-273 (2020).b DOI: https://doi.org/10.1038/s41586-020-2012-7

Bisso-Andrade, Aland. (2020). COVID-19: Un reto más allá de lo imaginable. Revista de la Sociedad Peruana de Medicina Interna. Vol. 33(3): 93-95. DOI: https://doi.org/10.36393/ spmi.v33i3.543

Martínez-jurado, Pedro y Meléndez-Alfaro, Fátima. (2020). Vulnerabilidad y percepción: una aproximación antropológica al Covid-19 en El Salvador. Periferia Revista de recerca i formació en antropologia. Vol. 25(2): 179-190. DOI: https://doi.org/10.5565/rev/periferia.771

Trujillo-Pérez, Joel. (2020). La vida social del Covid-19: una etnografía del escepticismo y el negacionismo en poblaciones informales de Ciudad de México. Periferia Revista de recerca i formació en antropologia. Vol. 25(2):141 153. DOI: https://doi.org/10.5565/rev/periferia.773

Florentín, Rosaura., Maldonado, Eufrosina y Portillo, Silvia. (2020). Escepticismo de comunidades rurales ante el Covid-19. Academic Disclosure. Vol. 1 (1): 15-23. Recuperado de https://revistascientificas.una.py/ojs/index. php/rfenob/article/view/134

Clavellina-Miller, José y Domínguez-Rivas, Mario. (2020). Implicaciones económicas de la pandemia por COVID-19 y opciones de política. Notas Estratégicas. No. 81: 1-11. Recuperado de http://bibliodigitalibd.senado.gob.mx/ handle/123456789/4829

García-Muñoz, Cecilia., Pérez-Sánchez, Beatriz y NavarreteTorres, María. (2020). Las empresas ante el Covid-19. GISST Revista de Investigación en Gestión Industrial, Ambiental, Seguridad y Salud en el Trabajo. Vol. 2(2): 85-143. Recuperado de http://editorialeidec.com/revista/index.php/ GISST/article/view/83

Médicos Sin Fronteras (2021). Nuestro trabajo en México. Recuperado de https://www.msf.mx/msf-en-mexico

\section{Cynthia Marisol Vargas Orozco}

Afiliación: Universidad Autónoma de Tamaulipas Doctorado en Políticas Públicas. Maestría en Criminología y Ciencias Forenses Licenciatura en Criminología. Coordinadora de la Licenciatura en Criminología. Catedrática de la Licenciatura y de la maestría en criminología ciencias forenses PNPC. Integrante del Cuerpo Académico Consolidado

\section{Karla Villarreal Sotelo}

Afiliación: Universidad Autónoma de Tamaulipas Doctorado en Derecho. Maestría en criminología y ciencias forenses. Licenciatura en criminología. Líder Del cuerpo académico de criminología consolidado. Jefa de posgrado. Catedrática de la licenciatura en criminología y maestría en criminología y ciencias forenses. Presidenta de la Sociedad Mexicana de Criminología filial Tamaulipas 